\title{
Numerical study of aerodynamics and brown coal combustion in the vortex furnace with air excess variation
}

\author{
Denis Krasinsky ${ }^{1, *}$ \\ ${ }^{1}$ Kutateladze Institute of Thermophysics SB RAS, 630090 Novosibirsk, Russia
}

\begin{abstract}
The results of numerical modelling of 3D turbulent two-phase reacting flow with account for all the principal heat and mass transfer processes during the pulverized brown coal combustion in the vortex furnace of a power plant boiler unit have been presented. For two computational cases where air excess coefficient $\alpha$ was varied (set to 1.15 and 1.25), the detailed aerothermochemical 3D structure of reacting flow in the furnace volume has been revealed. The comparison of integral heat engineering parameters and NOx emissions obtained in the two cases has shown a slightly improved vortex furnace performance in the case $\alpha=1.25$.
\end{abstract}

\section{Introduction}

Development of modern furnace devices matching the demands for clean and efficient coal combustion at thermal power plants is vital for heat power engineering [1]. With this aim, it is necessary to apply prospective scientific approaches to elaboration of projectible coalfired furnaces. In this context, taking into account the need to utilize the brown and lowrank coals, one of the promising approaches is the technology of pulverized coal combustion in vortex flow, implemented in a so-called vortex furnace [2]. The vortex furnace basic design, developed in earlier years at the Central Boiler and Turbine Institute (CBTI-design) [2], consists of the following main elements (see Figure 1): the vortex combustion chamber located in the lower part of the furnace, the diffuser, and the cooling chamber in the upper part of the furnace device. The input stream of coal-air mixture is supplied through the rectangular nozzle located over combustion chamber (before the diffuser). Thus the primary swirl (vortex) flow in the combustion chamber is formed by the tangential injection of fuel-air input jet. In this vortex furnace design a clear functional distinction is assumed between the combustion chamber (with refractory-lined walls) where the high-temperature pulverized coal combustion regime with liquid slag removal takes place, and the upper-part cooling chamber packed with heat-receiving water-walls.

In the previous research works the complex experimental and numerical studies on aerodynamics and turbulent flow features have been carried out at laboratory-scale vortex furnace model in isothermal formulation [2, 3]. It has been concluded there that aerodynamic features of the swirl flow inside the vortex combustion chamber provide the

* Corresponding author: $\underline{\mathrm{dkr} @ \text { itp.nsc.ru }}$ 


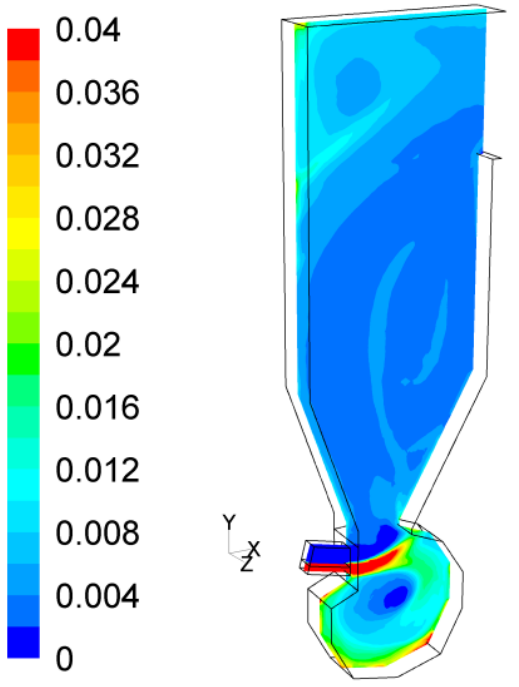

Fig. 1. 3D-view of the vortex furnace and the field of disperse phase concentration in $\mathrm{XY}$-section across nozzle center, $\mathrm{kg} / \mathrm{m} 3$.

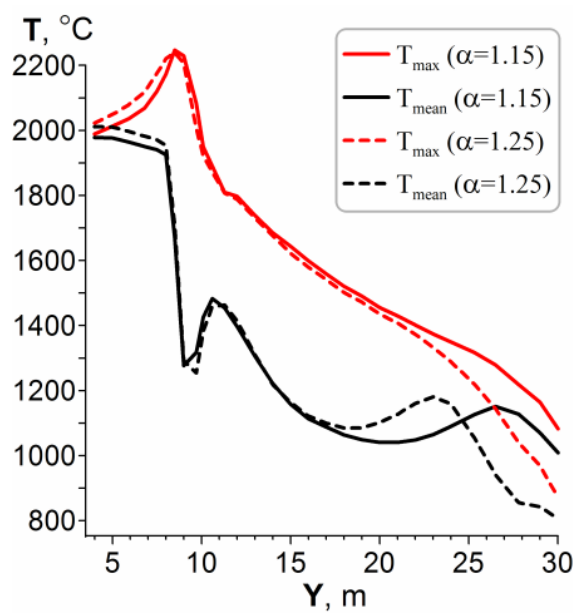

Fig. 2. Distributions of maximum temperature (red lines) and the temperature averaged over $X Z$-sections (black lines), along the vortex furnace height, ${ }^{\circ} \mathrm{C}$. Cases of air excess $\alpha=1.15$ (solid lines) and $\alpha=1.25$ (dashed lines).

following advantages during the coal-firing process: - stable structure of two-phase reacting flow; - prolonged residence time of coal particles, thus facilitating the completeness of coal burnout; - intensified heat- and mass-transfer due to enhanced mixing and high temperature level (this also allows to reduce the size of the furnace and entire boiler unit at the furnace design stage); - mitigation of $N O_{x}$ emissions due to the effect of recirculation of combustion products towards reaction zones inside the vortex chamber. Numerical simulation of the flow and pulverized-coal combustion processes in the full-size vortex furnace has been performed in [4] on the basis of Euler-Euler description for the both carrier gas and disperse phases, however, only monodispersed coal particles were considered in [4]. The numerical modelling of coal-firing processes in the full-size vortex furnace has also been carried out in [3] with the use of Euler-Lagrange approach which enables to represent in details (e.g. in 100 fractions by size, or more) the polydispersity of coal particles fed into the furnace.

Two new modifications of the basic vortex furnace design were proposed and studied [5-7] at the Institute of Thermophysics SB RAS. These enhancements (called a dual-nozzle design) are characterized by additional tangential-injection nozzles mounted at the bottom or at the upper part of the vortex combustion chamber, allowing for more flexible control of the aerodynamic structure and the furnace regime parameters. Nevertheless, a principal improvement of the working performance hasn't yet been achieved for the new dual-nozzle vortex furnace modifications, compared to the single-nozzle CBTI-design of the vortex furnace, and further research is still necessary.

\section{Mathematical model and computational results}

The presented work is a continuation of the previous research [3] and is devoted to numerical investigation of two operational regimes of combustion of Mongolian brown coal from Shiwei-Ovoo deposit [8] differing by air excess coefficient $\alpha$ in the vortex furnace of CBTI-design. Mathematical formulation of 3D turbulent two-phase reacting flow is based on Euler-Lagrange approach. The Favre-averaged governing equations of momentum, enthalpy and species concentration transport for carrier gas phase are closed with "realizable $k-\varepsilon$ " model of turbulence [9]. The gas phase mixture is represented by the 
following species: $\mathrm{O}_{2}, \mathrm{CH}_{n} \mathrm{O}_{m}, \mathrm{CO}, \mathrm{CO}_{2}, \mathrm{H}_{2} \mathrm{O}, \mathrm{N}_{2}$. The radiation energy transport equation is based on the use of $P_{1}$ approximation and WSGGM model for absorption coefficients. The coal composition is presumed to consist of volatiles, ash and free carbon. During Lagrangian tracking of polydispersed coal particles the heterogeneous reactions of the volatiles pyrolysis and the coke combustion are taken into account. The numerical solution was obtained on unstructured computational grid consisting of 254848 hexahedral cells. The interphase exchange of mass, momentum and heat transfer is accounted following the Particle-Source-In-Cell method [10]. Detailed description of the used models, assumptions, boundary conditions and numerical algorithm is given in [3, 6]. Computations were performed with the use of CFD package FLUENT.

For the studied full-size vortex furnace, the diameter of its combustion chamber is DF $=$ $6.2 \mathrm{~m}$ and the bounding dimensions of computational domain are: $\mathrm{X} \max =8.2 \mathrm{~m}, \mathrm{Ymax}=$ $30.6 \mathrm{~m}, \mathrm{Zmax}=2 \mathrm{~m}$. The diffuser neck width ratio is $\mathrm{Hx} / \mathrm{DF}=0.4$. The burner nozzle inclination angle to horizon (XZ plane) is $15^{\circ}$ and the nozzle inlet cross-section size is $1.2 \times 0.7 \mathrm{~m}$ (where the latter dimension is the width in $\mathrm{z}$-direction). The prescribed load of dry Shiwei-Ovoo coal [8] was $3 \mathrm{~kg} / \mathrm{s}$ (per computed half-section of the vortex furnace), the corresponding heat release rate is $68.6 \mathrm{MW}$. To assign the fractional composition of pulverized coal, the known Rosin-Rammler formula was applied, where the grinding polydispersity degree was presumed as 1.2 and the coal grinding fineness parameter R90 $=12 \%$. The two computational variants were performed for the furnace air excess coefficient set to $\alpha=1.15$ and $\alpha=1.25$.

Detailed aerothermochemical 3D structure of a reacting flow in the vortex furnace volume was obtained from variant numerical predictions, including the fields of velocity, temperature, species and dispersed phase concentrations, and heat fluxes. Some of these results are presented in Figures 1-3. The field of disperse phase concentration in XYsection $(\mathrm{z}=1 \mathrm{~m})$ across the nozzle center, shown in Figure 1, represents the evolution of pulverized-coal polydisperse stream released from the nozzle. It is observed that intensive heating of the lower "border" of this two-phase stream occurs due to the hot swirl flow below it (in the vortex combustion chamber). Then the volatiles burnout takes place nearby or downstream this lower "border", leading to the ignition of free carbon content in the coke particles. From Figure 2, where the profiles of maximum temperature Tmax and the temperature Tmean averaged over horizontal XZ-sections are depicted along the vortex furnace height for the two cases of air excess, the high-temperature level inside the vortex combustion chamber can be seen (with Tmax reaching $2200^{\circ} \mathrm{C}$ due to adiabatic conditions at the combustion

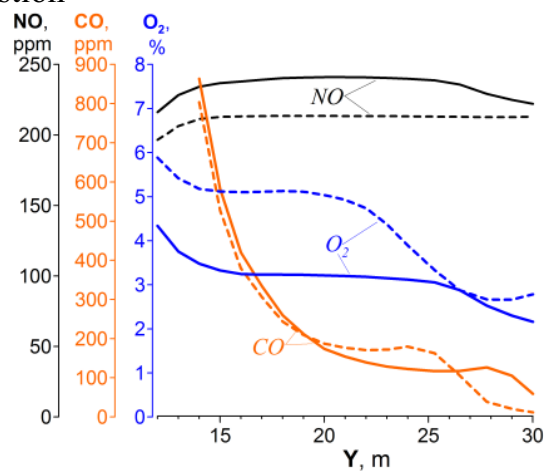

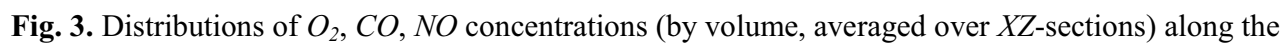
height of the vortex furnace cooling chamber. Cases of air excess $\alpha=1.15$ (solid lines) and $\alpha=1.25$ (dashed lines). 
chamber walls) - this provides the stable regime of liquid slag removal. For the case $\alpha=1.25$, a more rapid decrease of maximum temperature Tmax can be observed inside the cooling chamber. The profiles of $\mathrm{O}_{2}, \mathrm{CO}, \mathrm{NO}$ concentrations averaged over $\mathrm{XZ}$-sections are plotted in Figure 3 along the height of the vortex furnace cooling chamber, thus indicating the effect of air excess variation. The integral heat engineering and ecological parameters obtained in the outflow section of the studied vortex furnace are given in Table 1 for the two computational cases.

Table 1. Parameters at the vortex furnace outlet (averaged over the outflow section $x=8.2 \mathrm{~m}$ ).

\begin{tabular}{|c|c|c|}
\hline Parameter & Case $\boldsymbol{\alpha}=\mathbf{1 . 1 5}$ & Case $\boldsymbol{\alpha}=\mathbf{1 . 2 5}$ \\
\hline Mean temperature $T_{\text {mean }},{ }^{\circ} \mathrm{C}$ & 1045 & 988 \\
\hline $\mathrm{O}_{2}$ concentration, vol. $\%$ & 2.63 & 3.34 \\
\hline $\mathrm{CO}$ concentration, ppm & 56.0 & 62.6 \\
\hline Coke burnout incompleteness coefficient $q_{4}, \%$ & 1.20 & 1.17 \\
\hline $\mathrm{NO}_{2}$ emission $\left(\right.$ at $\left.6 \% \mathrm{O}_{2}\right), \mathrm{mg} / \mathrm{N} \mathrm{m}^{3}$ & 390 & 372 \\
\hline
\end{tabular}

\section{Conclusions}

The comparison of integral parameters of pulverized brown coal combustion in the vortex furnace, based on the numerical predictions for two cases of air excess, has shown (see Table 1) that the higher air excess coefficient leads to lower temperature at the outflow, slightly better carbon burnout, and also to somewhat lower $N O_{x}$ emission. This allows to conclude on a slightly improved vortex furnace performance in the regime with $\alpha=1.25$. Nevertheless in both variants the obtained heat engineering and ecological parameters of the studied vortex furnace meet the requirements used in thermal engineering practice.

This work was financially supported by the Russian Science Foundation (project no. 14-29-00093).

\section{References}

1. V.E. Nakoryakov, J. Eng. Thermophys. 23, 171 (2014)

2. V.V. Salomatov, D.V. Krasinskii, Yu.A. Anikin, I.S. Anufriev, O.V. Sharypov, Kh. Enhzhargal, J. Eng. Phys. Thermophys. 85, 282 (2012)

3. S.V. Alekseenko, I.S. Anufriev, V.G. Glavniy, D.V. Krasinsky, V.V. Rakhmanov, V.V. Salomatov, E.Yu. Shadrin, Heat Transfer Research 47, 653 (2016)

4. D.V. Krasinsky, Int. Rev. Mech. Eng. (I.RE.M.E.) 9, 507 (2015)

5. D.V. Krasinsky, V.V. Salomatov, I.S. Anufriev, O.V. Sharypov, E.Yu. Shadrin, Yu.A. Anikin, Thermal Eng. 62, 117 (2015)

6. D.V. Krasinsky, V.V. Salomatov, I.S. Anufriev, O.V. Sharypov, E.Yu. Shadrin, Yu.A. Anikin, Thermal Eng. 62, 208 (2015)

7. D.V. Krasinsky, O.V. Sharypov, J. Eng. Thermophys. 24, 348 (2015)

8. A.S. Zavorin, A.Yu. Dolgikh, V.V. Salomatov, S. Batmunkh, Kh. Enkhzhargal, Bulletin of Tomsk Polytechn. Univ. 324, 47 (2014)

9. T.-H. Shih, W.W. Liou, A. Shabbir, Z. Yang, J. Zhu, Computers \& Fluids 24, 227 (1995)

10. C.T. Crowe, M.P. Sharma, D.E. Stock, ASME J. Fluids Eng. 99, 325 (1977) 